\title{
Mill evaluation of an intensified mechanical pulping process
}

\section{Christer Sandberg, Jan-Erik Berg and Per Engstrand}

KEYWORDS: Process Intensification, Double disc refining, Chip pretreatment, Low consistency refining, High intensity, Process control, Energy efficiency, Mechanical pulping, TMP

ABSTRACT: Mill-scale demonstration of a process concept inspired by Process Intensification (PI) principles was performed in Holmen Paper Braviken mill, Norrköping, Sweden. The intensified process consists of wood softening by means of chip pretreatment with sodium sulphite, high intensity refining followed by low consistency refining. This process yields very low shives content and thus the unit operations screening and reject refining can be eliminated and the pulp is fed directly to the paper machine.

Thorough evaluation of key paper- and print quality data showed that it is possible to produce pulp for newsprint at $1500 \mathrm{kWh} / \mathrm{adt}$ total specific energy (including auxiliary drives such as pumps, screw feeders, etc.). The total specific energy consumption was 900 $\mathrm{kWh} /$ adt lower compared to the normal process used for newsprint in Braviken, and $500 \mathrm{kWh} /$ adt lower compared to today's best available technology. The auxiliary equipment energy demand was $120 \mathrm{kWh} / \mathrm{adt}$, which was less than half of that of the reference TMP line. The PIinspired process reduces the number of machines drastically compared to a conventional TMP line, as well as the number of pumps, chests and other auxiliary equipment.

ADDRESSES OF THE AUTHORS: Christer
Sandberg (christer.sandberg@holmenpaper.com):
Holmen Paper AB, Paper Product Development,
SE-601 88 Norrköping, SWEDEN. Jan-Erik Berg
(jan-erik.berg@miun.se), and Per Engstrand
(per.engstrand@miun.se): Mid Sweden University,
FSCN, Department of Chemical Engineering,
SE- 851 70, Sundsvall, SWEDEN.
Corresponding author: Christer Sandberg

Process Intensification (PI) is a concept used in the chemical process industry for process development. There is no strict definition of PI, but generally the development should lead to large changes in one or more of: number or size of equipment, yield, energy consumption or amount of waste. Van Gerven and Stankiewicz (2009) have summarized the basic features of PI in a comprehensive way.

In the opening speech of the first international conference on Process Intensification, Ramshaw (1995) pointed out the need of designing chemical reactors with high selectivity, delivering only the wanted substances and he ended with: "This would facilitate delivery of a high quality product without an expensive downstream purification sequence".

Block symbols used in figures are shown in Fig 1.

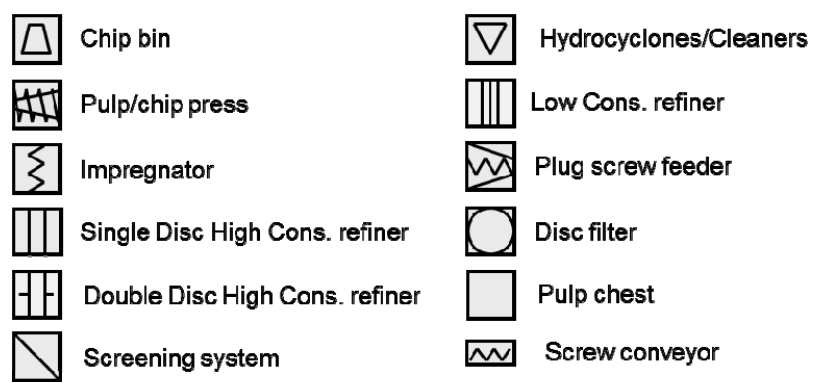

Fig 1 - Block symbols used in figures.

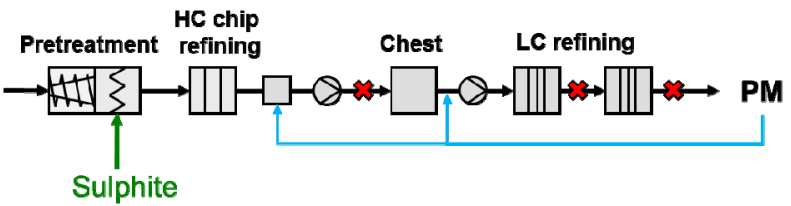

Fig 2 - A schematic flow-sheet of the intensified process, CPTHC-LC.

The mechanical pulping processes are rather complex today with many unit operations. A lot of energy is consumed, not only in refining, but also in pumping, screening and in reject processing. In this work we have evaluated an intensified process based on earlier work by Sandberg and co-workers (2011). The process, Fig 2, consists of three main-line unit operations and the whole reject system, the "downstream purification sequence", is excluded. The concept includes:

1. Low dose sulphite chip pretreatment (CPT).

2. High intensity high consistency (HC) refining

3. Low Consistency (LC) refining.

This process is here called CPT-HC-LC.

The CPT-HC-LC process actually resembles to some extent one of the earliest refiner based mechanical pulping processes developed by the Bauer Company during the mid-1950's (Eberhardt 1955), Fig 3. After pretreatment in a "Pressafiner" water was added to the fiberized chips before they were refined in double disc (DD) refiners at $30-45 \%$ consistency. The refined pulp was mixed with screen reject and refined at low to medium consistency (LC/MC: 4-8\%). The pulp was diluted in a chest and fed to screening. Thereafter the screen accept was cleaned in a two-stage system. DD refining was considered to be much better than single disc (SD) refining due to the much lower shives content and lower energy consumption.

The pulp produced was called "Refiner Groundwood" when it was introduced and later Refiner Mechanical Pulp (RMP). In this early RMP process the primary refining was made with an open discharge system (not pressurized) and the process included a reject processing system.

The concept of omitting the reject system has been evaluated in mill scale earlier (Skinnar 1979). This idea emerged from the introduction of the thermomechanical pulping (TMP) process (Asplund, Bystedt 1973), which 


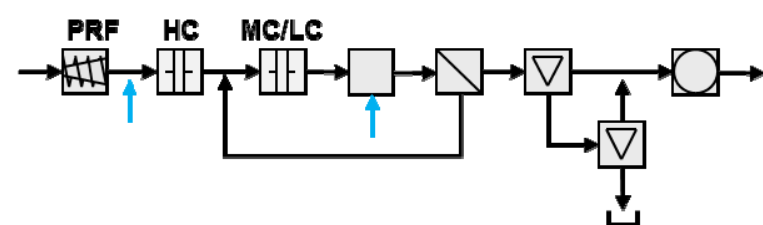

Fig 3 - The first Bauer RMP process (redrawn from Eberhardt 1955). PRF = Pressafiner.

yielded a pulp with much lower shives content than the RMP process. The demands on paper quality was much lower at that time, though.

A prerequisite for a process without a reject system is that a pulp with low shives content and well fibrillated fibre fraction can be achieved in the main line refining. Earlier work has shown that reduced energy consumption, increased production and reduced shives content can be achieved at maintained tensile index and light scattering. This is accomplished with wood softening by increased temperature and/or sulphonation combined with increased "refining intensity" by using a feeding segment design (Nelsson et al. 2014). Comparable results have also been shown by Hill et al. (2009).

Using LC refining as second stage in a TMP process has been presented earlier, (Flowers et al. 1979, Bonham et al. 1983, Engstrand et al. 1990 and 1991). There are some important advantages with second stage LC refining for this process; the LC refiner will perform the fibre development that is usually attained over the reject refining system, shives coming from the first stage are reduced and the energy demand of LC refining is around $50 \%$ lower than HC refining (Sandberg et al. 2016).

The hypothesis of this work was that a combination of improved chip-refining and low consistency refining should make it possible to eliminate the unit operations of screening and reject refining. The hypothesis was tested in a mill scale trial including pulp and paper production as well as printing of commercial newspapers.

\section{The CPT-HC-LC process}

Below, the process inspired by Process Intensification is described in more detail.

Sulphite chip pretreatment. Sulphite is added to the chips in an impregnator after compression to get good impregnation. It is enough with a low sulphite dose (5-10 $\mathrm{kg} / \mathrm{bdt}$ at $\mathrm{pH} 9$ ) to increase strength properties and reduce shives content (Nelsson et al. 2015).

Improved $\boldsymbol{H C}$ refining. Refining is made with high intensity refiners, such as DD or RTS. The wood softening and partial structural breakdown of chips that is attained with the pretreatment makes it possible to increase intensity and production rate in chip refining by means of feeding segment design (Nelsson et al. 2014). Chip refining should preferably be made at 6-7 bar (Sabourin et al. 1997, Muhic et al. 2010, Nelsson et al. 2016). After each chip refiner, pulp should be diluted in a dilution screw connected to a stand-pipe or in a small pulper, to enable good on-line quality measurement and fast feed-back control of the chip refiners.

LC refining. After $\mathrm{HC}$ refining, the pulp is refined at low consistency. No latency chest is needed, since LC refining removes "latency" efficiently, (Welsh 1999), just a small chest to handle the start and stop of LC refiners. Earlier work has has shown that it is beneficial for pulp quality and energy efficiency to combine LC refining with high intensity refining, e.g. DD or RTS refining (Andersson et al. 2010, Sandberg et al. 2016). It is preferable to do the LC refining in two stages, as shown in Fig 2, with the first stage adapted for shives reduction and the second stage for fibre development (Luukkonen 2014).

No reject treatment. The $\mathrm{CPT}-\mathrm{HC}-\mathrm{LC}$ process gives a shives content that is similar to a conventional single disc $\mathrm{HC}$ refining process for newsprint with screening and reject refining (Andersson 2011).

Thus, after LC refining the pulp is pumped directly to the paper machine without screening and reject refining. This eliminates a number of chests, pumps, screens, reject dewatering and all equipment connected to $\mathrm{HC}$ reject refining.

Removing the whole reject system reduces the number of equipment more than what is added by the chip pretreatment and sulphite dosing systems. Thus, both investment and maintenance cost will be lower for the CPT-HC-LC process compared to a standard process. Since several pulp chests and pulp circulation are removed, process control will be easier due to reduced time delay in the system.

\section{Materials and methods}

A trial was performed in September 2015 in the Holmen Paper Braviken mill, Norrköping, Sweden. The evaluation included pulp production, paper production and printing at two print houses.

The trial was made with $100 \%$ Norway spruce round wood. Chips were presteamed, washed and treated with sulphite in an Impressafiner before being refined in two parallel double disc refiners. After $\mathrm{HC}$ refining the pulp was LC refined and fed to the paper machine.

Sulphite dosing system. A sulphite dosing system was installed, shown in Fig 4. The sodium sulphite $\left(\mathrm{Na}_{2} \mathrm{SO}_{3}\right)$ solution was prepared by mixing fresh water with concentrated sodium bisulphite $\left(\mathrm{NaHSO}_{3}\right)$ and sodium hydroxide $(\mathrm{NaOH})$. The mixture was pumped via a daytank to the impregnator after an Impressafiner (MSD 500, Andritz). Dosing was controlled by a flow meter and valve after the dosing pump and adjusted to the speed of the feeding screw (production) before the Impressafiner, described in detail by Nelsson (2016). The sodium sulphite charge reported was based on the refiner production rates though, which were calculated from standpipe flow and consistency.

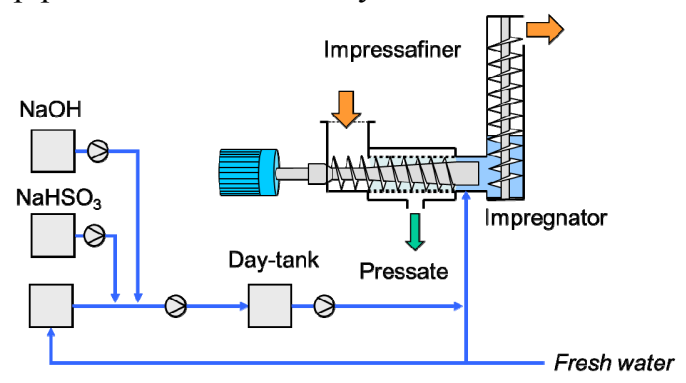

Fig 4 - Sulphite dosing system 


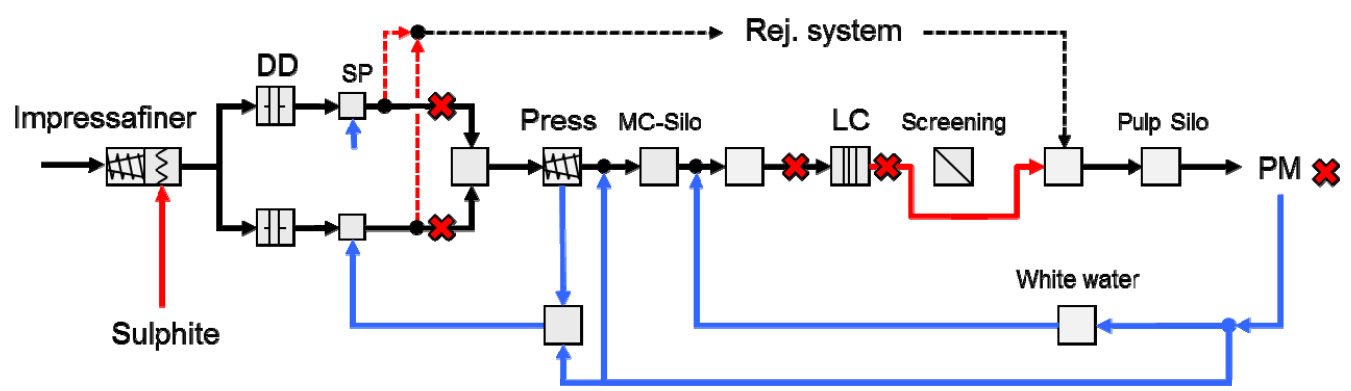

Fig 5 - Process configuration for CPT-HC-LC trial. Blue lines are white water Red lines are new piping for the trial and dashed lines are start/stop pulp flows. Pulp sampling points are marked with red $\mathrm{X}$.

Start/stop pulp. When refiners are started and stopped, they always produce coarse pulp for a short time. We wanted to avoid that such coarse pulp was fed to the LC refiner and to manage this, pipes and valves to take care of start and stop pulp were installed, dashed lines in Fig 5. Normally start and stop pulp is a very small part of the production, but occasionally problematic situations can emerge and we wanted to avoid that risk during the trial.

The start and stop pulp was pumped to a reject system and the plan was to start the reject refining if it was needed during the trial. The trials went without any major problems, thus the reject refining system was never started. New piping was also installed to make it possible to by-pass the screen room.

Mill scale trial. The flowsheet for the trial is shown in Fig 5. For the CPT-HC-LC trial, $7.7 \mathrm{~kg}$ sulphite/adt (as $\mathrm{Na}_{2} \mathrm{SO}_{3}$ ) was added to the impregnation liquor (fresh water) entering the impregnator after the Impressafiner. The sulphite solution, concentration $150 \mathrm{~g} / \mathrm{l}$, was prepared by mixing water, concentrated sodium bisulphite and sodium hydroxide to $\mathrm{pH} 9$.

The treated chips were fed to two parallel RGP68DD refiners (Valmet) equipped with feeding segments from Andritz (72DD563ACU on control-side and 72DD573ABD on feed-side). The pulp was diluted to around $8 \%$ consistency after each refiner and pumped from stand-pipes to a wash-press where the pulp was pressed to around $30 \%$. After the press, the pulp was diluted with PM white-water to $4.5 \%$ consistency. The diluted pulp was LC refined with a TwinFlo 72 refiner (Andritz). After LC refining, pulp was pumped to the pulp silo at PM52. A more detailed description of the TwinFlo 72 refiner has been made by Andersson (2011). The LC refiner was equipped with LemaxX TC111/112 segments from Andritz. The flow through the refiner was $230 \mathrm{l} / \mathrm{s}$ and the flow forward was around $190 \mathrm{l} / \mathrm{s}$, i.e. there was a $17 \%$ recirculation around the refiner. Temperature of the feed pulp was $61^{\circ} \mathrm{C}$. Refining power was $3 \mathrm{MW}$, resulting in a specific edge load of $0.8 \mathrm{~J} / \mathrm{m}$.

All levels in towers and chests were lowered to a minimum to make the shift to CPT-HC-LC pulp faster

Reference samples were taken on the same day just before the trial from the single disc (SD) TMP line, Fig 6, that normally supplies PM52 with pulp.

Samples were taken from final pulp and produced paper and reels were taken for print trials.

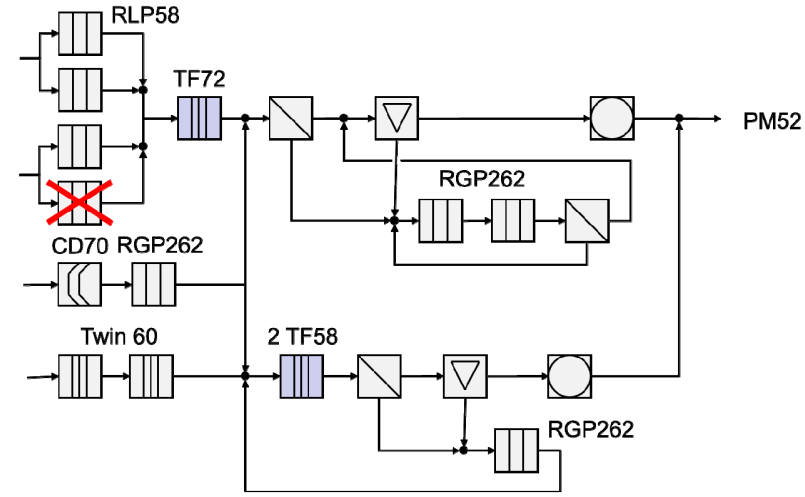

Fig 6 - Block diagram for the TMP line that normally supplies PM52. LC refiners are bluish. One of the four RLP58 refiners was not running during the reference trial.

\section{Pulp and paper analyses}

All pulp and paper analyses were made in the mill laboratory in Braviken. All pulp samples were gathered as composite samples during $30 \mathrm{~min}$. From the mixed samples, two sub-samples were taken and tested. Tensile index was measured based on an increased number of strips (16 strips instead of 8). Presented pulp data is averages of the double testing. For the reference and trial paper, samples were taken from three consecutive tambour reels during two hours. Averages from the three tambour reels are presented. Paper samples were analysed with Autoline (Lorentzen \& Wettre)

\section{Results}

Process data for the CPT-HC-LC and reference trials are shown in Table 1.

The specific energy consumption (SEC) for the reference TMP was $2155 \mathrm{kWh} /$ adt. Auxiliary energy (pumps, screens, presses, etc.) was $250 \mathrm{kWh} / \mathrm{adt}$, which resulted in a total energy consumption of about 2400 $\mathrm{kWh} /$ adt.

For the CPT-HC-LC trial the Impressafiner SEC was 20 $\mathrm{kWh} / \mathrm{adt}$ and the total SEC was $1395 \mathrm{kWh} / \mathrm{adt}$. The total specific refining energy was based on the production after the LC refiner. Auxiliary energy (pumps, screens, presses, etc.) was $120 \mathrm{kWh} /$ adt, which resulted in a total energy consumption of about $1500 \mathrm{kWh} / \mathrm{adt}$, which was $900 \mathrm{kWh} /$ adt lower than the reference TMP. This process has around $10 \%$ lower energy consumption (200 $\mathrm{kWh} / \mathrm{adt}$ ) compared to a conventional HC SD TMP process due to the installed LC refiners. 
Table 1 - Process data

\begin{tabular}{llclcc}
\hline & & DD2 & DD3 & LC & Ref. \\
\hline Feed pressure & bar & 4.8 & 5.2 & & \\
Housing pressure & bar & 5.0 & 5.0 & & \\
Plate gap & $\mathrm{mm}$ & 0.59 & 0.68 & & \\
Blow line consistency & $\%$ & 27 & 26 & & \\
Power & $\mathrm{MW}$ & 21.4 & 18.6 & 3.0 & 68 \\
Pulp flow & $\mathrm{l}$ & 40.7 & 51.6 & 188 & 170 \\
Stand-pipe cons. & $\%$ & 10.3 & 6.95 & 4.1 & 4.6 \\
Production* & adt/h & 16.8 & 14.3 & 30.8 & 31.6 \\
SEC & $\mathrm{kWh} /$ adt & 1276 & 1297 & 97 & 2155 \\
\hline
\end{tabular}

*Production rate for the DD refiners was calculated from flow and consistency measured after the stand-pipe for each refiner

At the beginning of the trial, it was difficult to run the refiners at constant load which resulted in poor pulp and paper quality. We realized that the instability was caused by the high housing pressure, 6.5 bar. The reason why we wanted to run at high temperature (pressure) was because earlier experience had shown that this running mode can reduce SEC by about $150 \mathrm{kWh} / \mathrm{adt}$ mainly due to further increased softening combined with lower disc gap (Muhic et al. 2010). When we lowered the pressure to 5 bar the load variations were reduced and pulp and paper properties improved. For one of the refiners, we managed to reach almost $17 \mathrm{adt} / \mathrm{h}$, the other had new segments (changed right before the trial) and was impossible to feed more than $14.3 \mathrm{adt} / \mathrm{h}$. The final pulp production was around $31 \mathrm{adt} / \mathrm{h}$ during the whole trial.

\section{Pulp properties}

The CPT-HC-LC pulp had tensile index $52 \mathrm{Nm} / \mathrm{g}$, Fig 7, which is a normal level for newsprint in Braviken. In the figure, data from a TMP-line consisting of two-stage (main and reject line) HC SD refining is included as an additional reference (data from Sandberg et al. 2016). All pulp properties are shown in Table 2.

Tensile index was similar for reference and CPT-HCLC pulp. The CPT-HC-LC pulp had higher freeness and light scattering but lower fibre length and tear index compared to reference pulp. Shives content, measured with PulpEye was higher for the CPT-HC-LC pulp compared to the reference. The load on the LC refiner was somewhat too high, which resulted in a little more fibre length reduction than anticipated.

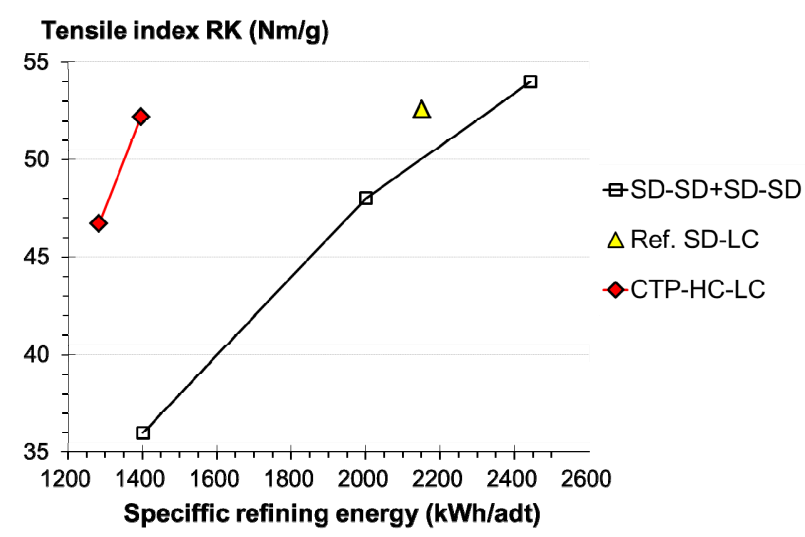

Fig 7 - Tensile index for the CPT-HC-LC process and the SD$L C$ references versus specific refining energy. The data for the SD-SD+SD-SD process is from Sandberg et al. (2016).

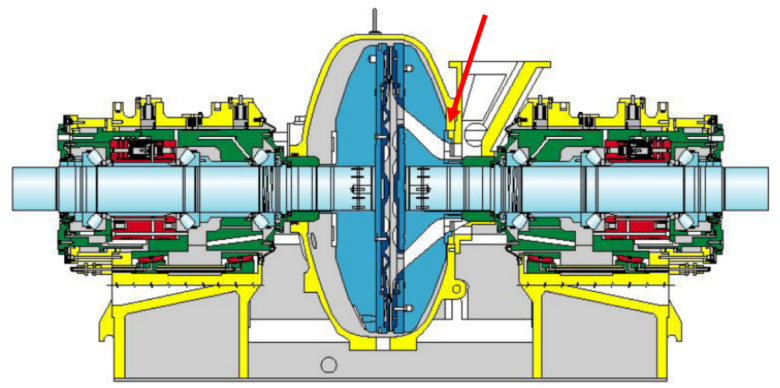

Fig 8 - RGP68DD refiner cross section. Red arrow show where large shives can pass through the sealing from the chip feed to the refiner housing and refined pulp.

The amount of large shives was higher than expected, especially at the beginning of the trial when we tried to run high pressure in the DD refiners. These large shives did most likely come from leakage in the sealing between rotor and refiner housing where chips are fed into the refiner, Fig 8 .

At the maintenance shut a week after the trial it was found that one of the feed pressure transmitters was not properly calibrated, which means that the differential pressure (feed - housing pressure) over one of the refiners was higher than normal. This might have contributed to more large shives than normal.

\section{Paper properties}

During the whole trial, including reference production, the PM was producing $42 \mathrm{~g} / \mathrm{m}^{2}$ standard newsprint. Unfortunately the paper machine speed had to be reduced from $1621 \mathrm{~m} / \mathrm{min}$ during the reference run down to 1425 $\mathrm{m} / \mathrm{min}$ for the CPT-HC-LC trial. This was due to the initial problems in TMP when we tried to run the refiners at high pressure. The reduced speed might have resulted in somewhat higher strength properties than the normal speed. The levels in pulp silos were extremely low (below 5\% in pulp and broke silos) at the shift of pulp, which made the change in pulp quality very fast. The first couple of hours were not stable due to the initial coarse pulp. The PM was running at stable conditions with CPTHC-LC pulp for four hours. Paper samples were taken during one and a half hour, starting four hours after the shift of pulp. There were no web breaks during the CPTHC-LC trial or during the reference trial.

In Table 3, paper properties are shown for CPT-HC-LC paper and reference. The values are averages from three tambour. Even though the freeness was higher (Table 2) for the CPT-HC-LC pulp, the air permeance and surface roughness was lower for the CPT-HC-LC paper. All properties were equal or somewhat better for the CPTHC-LC paper, except tear index.

\section{Printing}

Paper from the reference and CPT-HC-LC trial was printed in Coldset at two printers (Pressgrannar and $\mathrm{V}$-TAB). The paper was evaluated with respect to set-off, print through, miss-register, linting, etc. The CPT-HC-LC paper had equal or somewhat better printing properties compared to the reference. 
Table 2 - Pulp properties for CPT-HC-LC and reference trial

\begin{tabular}{|c|c|c|c|c|c|c|c|}
\hline & \multicolumn{4}{|c|}{ CPT-HC-LC } & \multirow{2}{*}{$\begin{array}{r}\text { Reference } \\
\text { SD-LC }\end{array}$} & \multirow[t]{2}{*}{ Method } \\
\hline & & DD2 & DD3 & Feed LC & After LC & & \\
\hline CSF & $\mathrm{ml}$ & 142 & 151 & 143 & 109 & 90 & ISO 5267-2 \\
\hline PulpEye, Fibre length & $\mathrm{mm}$ & 1.01 & 1.02 & 1.00 & 0.94 & 1.12 & \\
\hline PulpEye, Shives sum* & $\# / g$ & 462 & 391 & 406 & 385 & 277 & \\
\hline PulpEye, Long shives** & $\# / g$ & 160 & 125 & 152 & 109 & 49 & \\
\hline Tensile index ${ }^{* * *}$ & $\mathrm{Nm} / \mathrm{g}$ & 48.7 & 48.4 & 46.9 & 51.8 & 52.6 & ISO 1924-2 \\
\hline Elongation $^{* * *}$ & $\mathrm{~mm}$ & 2.02 & 2.12 & 2.11 & 1.95 & 1.89 & ISO 1924-2 \\
\hline Density ${ }^{* * *}$ & $\mathrm{~kg} / \mathrm{m}^{3}$ & 503 & 480 & 477 & 509 & 504 & ISO 534 \\
\hline Tear index ${ }^{* * *}$ & $\mathrm{Nm}^{2} / \mathrm{kg}$ & 6.4 & 6.7 & 6.8 & 6.0 & 7.0 & ISO 1974 \\
\hline Light scat. coef. $557 \mathrm{~nm}^{* * *}$ & $\mathrm{~m}^{2} / \mathrm{kg}$ & 51.9 & 54.1 & 53.3 & 53.2 & 50.1 & ISO 9416 \\
\hline
\end{tabular}

* Shives sum is the number of counted particles per gram wider than $75 \mu \mathrm{m}$ and longer than $0.3 \mathrm{~mm}$

** Long shives are the number of counted particles per gram wider than $75 \mu \mathrm{m}$ and longer than $1.5 \mathrm{~mm}$.

*** Handsheets were made according to ISO 5269-2, DIN 54358

Table 3 - Paper properties (averages and standard deviations of three tambour reels)

\begin{tabular}{lllll}
\hline Parameter & & CPT-HC-LC & Reference & Method \\
\hline Ash content & $\%$ & $9.3 \pm 0.06$ & $9.1 \pm 0.3$ & ISO 1762 \\
Moisture content & $\%$ & $8.6 \pm 0.1$ & $8.5 \pm 0.1$ & ISO 287:2009 \\
PM Speed & $\mathrm{m} / \mathrm{min}$ & 1425 & 1621 & \\
Air permeance & $\mathrm{ml} / \mathrm{min}$ & $215 \pm 15$ & $253 \pm 15$ & ISO 5636-3 \\
Density & $\mathrm{kg} / \mathrm{m}^{3}$ & $624 \pm 14$ & $618 \pm 6$ & ISO 534:2011 \\
Tear strength CD & $\mathrm{mN}$ & $271 \pm 7$ & $343 \pm 3$ & L\&W Autoline Tearing \\
TEA MD & $\mathrm{J} / \mathrm{m}^{2}$ & $19.2 \pm 0.1$ & $18.3 \pm 0.1$ & L\&W Autoline Tensile, similar to ISO 1924-2 \\
Elongation MD & $\mathrm{mm}$ & $1.06 \pm 0.01$ & $1.02 \pm 0.01$ & L\&W Autoline Tensile, similar to ISO 1924-2 \\
Tensile strength MD & $\mathrm{kN} / \mathrm{m}$ & $2.94 \pm 0.03$ & $2.94 \pm 0.02$ & L\&W Autoline Tensile, similar to ISO 1924-2 \\
Anisotropy & - & $3.52 \pm 0.04$ & $3.65 \pm 0.04$ & Tensile strength MD/CD \\
Thickness & $\mathrm{mm}$ & $72.3 \pm 1.5$ & $74 \pm 1.1$ & ISO 534:2011 \\
Light scattering coef. & $\mathrm{m} 2 / \mathrm{kg}$ & $56 \pm 0.1$ & $54.1 \pm 0.9$ & ISO 1916:2009 \\
Opacity & $\%$ & $94.6 \pm 0$ & $94.5 \pm 0.1$ & ISO 2471:2009 \\
ISO-Brightness & $\%$ & $58.3 \pm 0.1$ & $57.9 \pm 0.9$ & ISO 2470-1:2009 \\
Roughness 1kg BS & $\mathrm{ml} / \mathrm{min}$ & $89 \pm 4$ & $109 \pm 3$ & ISO 8791-2 \\
Roughness 1 $\mathrm{kg}$ TS & $\mathrm{ml} / \mathrm{min}$ & $115 \pm 6$ & $129 \pm 3$ & ISO 8791-2 \\
\hline
\end{tabular}

Discussion

These trials showed that it is possible to produce pulp for newsprint with a total specific energy consumption of $1500 \mathrm{kWh} / \mathrm{adt}$, which was $900 \mathrm{kWh} / \mathrm{adt}$ (40\%) lower than the reference pulp. The reference system is however not today's BAT (Best Available Technology). A BAT process for newsprint consumes around $2000 \mathrm{kWh} / \mathrm{adt}$ at similar tensile index as the CPT-HC-LC pulp (Ferritsius et al. 2014). Thus, the CPT-HC-LC process had 25\% lower energy consumption than a BAT process.

The only problem that was identified during the trials was the large shives that slipped through the DD refiner sealing. Some of these shives were of the size of a match and they got stuck in the LC refiner segments, which gradually decreased outlet pressure from the LC refiner. It was not necessary to stop the trial, but it might have plugged the refiner if we would have continued longer. To be able to implement this process concept, this problem has to be addressed. After calibration of the feed pressure transmitter, the large shives was no longer detected. The housing sealing has to be changed on a regular basis to avoid this problem. If LC refining is made in two stages, the first refiner can be adapted for efficient shives reduction, which also would contribute to low shives content.

The new concept significantly simplified the process, which is emphasised in Process Intensification. A large number of unit operations, chests, pumps, valves and much more equipment were omitted. Two unit operations were added though; the Impressafiner and sulphite dosing system consisting of four equipment and four small tanks as well as four pumps and a few valves.

One idea that would simplify the proposed process even further and reduce the sulphite charge is to utilize the Impressafiner (MSD) as plug screw (PSF) and only have a small pressurized impregnator, Fig 9b. For the trial process, Fig $9 a$, around $50 \%$ of the sulphite is lost in the 
PSF (Nelsson 2016). It is important for good shives reduction to have uniform impregnation of chips.

\section{Implementation}

It should be possible to implement this technology for continuous production of newsprint. Of course the shive problem mentioned above has to be solved. The "intensified" process that was presented in this paper has been utilized for production of newsprint. If the $\mathrm{HC}$ and LC refining in this process is further optimized, it can most probably also be used for higher quality printing paper such as SC and LWC. In addition to this, screening at the paper machine could be utilized to reach very low shives content for improved grades. The reject can be refined at the paper machine in a small refiner or sent back to the pulp mill for reject treatment.

\section{Conclusions}

A mill trial showed that it is possible to produce pulp for newsprint with an intensified process consisting of chip pretreatment, improved high intensity $\mathrm{HC}$ refining and LC refining (CPT-HC-LC). The process was operating without screening or reject refining.

The CPT-HC-LC process concept has several advantages:

- Reduced refining energy

- Reduced amount of auxiliary energy

- Lower investment cost

- Lower maintenance cost

- Easier process control

The total electrical energy consumption (including auxiliary energy) for the CPT-HC-LC process was around $1500 \mathrm{kWh} / \mathrm{adt}$, which was $900 \mathrm{kWh} / \mathrm{adt}(40 \%)$ lower than the reference pulp and around 25\% lower than a BAT TMP process. The auxiliary electrical energy was reduced from 250 to $120 \mathrm{kWh} / \mathrm{adt}$.

Newsprint was produced from the CPT-HC-LC pulp with properties equal or somewhat better than reference paper, except tear index. The produced paper was printed in Coldset with similar or slightly better quality.

Two problems were identified during the trial; first, large shives slipped through the DD refiner sealing, although not in a quantity that caused any major problem with PM or printer runability though, second, it was not possible to run the refiners at high pressure (6.5 bar) using the feeding segments.

It should be possible to implement this technology for production of newsprint. With further optimization it may also be possible to use this concept for higher quality grades also

\section{Future work}

Process Intensification is an interesting concept in the way it has structured and improved the process development in the chemical process industry. It should be possible to apply a similar thinking in the pulp and paper industry, although the basic principles might to some extent be different.

We have initiated a work aiming at developing a PI concept for mechanical pulping which could be extended to other pulping and paper making processes in the future.
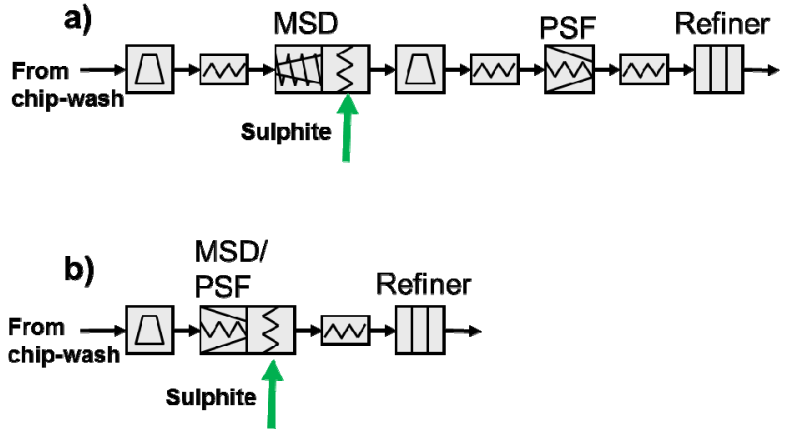

Fig 9 - a) Detail of the process used in the trial. b) Simplified impregnation process. MSD $=$ Impressafiner, $P S F=$ plug screw feeder.

\section{Acknowledgements}

The authors are most grateful to the people in the Braviken mill for letting us turn the mill upside down and to the Swedish Energy Agency, Knowledge Foundation and Holmen Paper AB for financial support and to Jan Hill for fruitful discussions and valuable comments on the manuscript. This work was made within the Swedish "Energy Efficient Mechanical Pulping Program".

\section{References}

Andersson, S. (2011): Low consistency refining of mechanical pulp - process conditions and energy efficiency, Thesis, Mid Sweden University, ISBN 978-91-86694-60-9.

Andersson, S., Sandberg, C. and Engstrand, P. (2010): Comparison of mechanical pulps from two stage $\mathrm{HC}$ single disc and $\mathrm{HC}$ double disc - LC refining, Appita J. 65(1), 57-62.

Asplund, A. and Bystedt, I. (1973): Development of the thermo-mechanical pulping method, Int. Mech. Pulping Conf., Stockholm, 15:1.

Bonham, J.S., Flowers, A.G. and Schofield, A.J., (1983): Post refining of P. radiata TMP, Appita J. 36(6), 466-470.

Eberhardt, L. (1955): New and revolutionary method for production of mechanical pulp - Groundwood from wood chips, Paper Trade J., 139(37), 26-28.

Engstrand, P., Hammar, L.-A., Htun, M., Pettersson, R. and Svensson, B. (1990): Framställning av mekanisk och kemimekanisk massa i två steg, Patent SE - 461103 (in Swedish), 1990-01-08.

Engstrand, P., Hammar, L. Å., Sjögren, B., Svensson, B., and Htun, M. (1991): A method of producing cellulosic pulp, Patent, WO 1991006700 A1. EP 0500674 A1, 1991-05-16.

Ferritsius, O., Mörseburg, K. and Ferritsius, R. (2014): BAT of CTMP and TMP plants with respect to quality development and energy efficiency, Int. Mech. Pulping Conf., Helsinki.

Flowers, A., Pearson, A. and Tyler, A. (1979): A preliminary report on single stage TMP pulping of $P$. radiata followed by post refining, Appita 33(3): 195-200.

Hill, J., Sabourin, M., Johansson, L. and Aichinger, J. (2009): Enhancing fiber development at reduced energy consumption using TMP sub-processes and targeted chemical application - Pilot and commercial scale results, Int. Mech. Pulping Conf. Sundsvall, 39-45.

Luukkonen, A. (2014): LC refining of high freeness CTMP, Int. Mech. Pulping Conf. Helsinki. 
Muhic, D., Sundström, L., Sandberg, C., Ullmar, M. and Engstrand, P. (2010): Influence of temperature on energy efficiency in double disc chip refining. Nord. Pulp Paper Res. J., 25(4), 420-427.

Nelson, E. (2016): Improved energy efficiency in mill scale production of mechanical pulp by increased wood softening and refining intensity, Ph.D. Thesis, Mid Sweden University, ISBN: 978-91-88025-59-3.

Nelsson, E., Sandberg, C., Svensson-Rundlöf, E., Muhic, D., Rohdén, L., Engberg, B. and Engstrand, P. (2014): Improved energy efficiency in thermomechanical pulping through cooptimization of intensity by segment design and wood softening by sulfonation, Int. Mech. Pulping Conf., Helsinki.

Nelsson, E., Sandberg, C., Svensson-Rundlöf, E., Engstrand, P., Fernando, D. and Daniel, G. (2015): Low dosage sulfite pretreatment in a modern TMP-line Nord. Pulp Paper Res. J, 30(4), 591-598.

Nelsson, E., Sandberg, C., Svensson-Rundlöf, E., Paulsson, M., Granfeldt, T., Engberg, B. and Engstrand, P. (2016): Mill scale production of TMP with double disk refining - The effects of a mild sulfonation, atmospheric preheating and refining temperatures, Int. Mech. Pulping Conf., Jacksonville, 182-186.

Ramshaw, C. (1995): The Incentive for Process Intensification, Proceedings, 1st Intl. Conf. Proc. Intensif. for Chem. Ind., 18, BHR Group, London, 1-2.

Sabourin, M., Xu, E., Cort, J. B., Boileau, I. and Waller, A. (1997): Optimizing residence time, temperature and speed to improve TMP pulp properties and reduce energy, Pulp Paper Canada, 98(4), T111-T118.

Sandberg, C., Sundström, L., Andersson, S. and Nelsson, E. (2011): New TMP-line improves pulp quality and reduces energy consumption. Int. Mech. Pulping Conf., Xian, 472-475.

Sandberg, C., Berg, J.-E. and Engstrand, P. (2016): System aspects on low consistency refining of mechanical pulp, Int. Mech. Pulping Conf., Jacksonville, 485-495.

Skinnar, R. (1979): One year's experience from single-stage pressurized refining of TMP for offset newsprint, Int. Mech. Pulping Conf., Toronto, 205-215.

Van Gerven, T. and Stankiewicz, A. (2009): Structure, Energy, Synergy, Time - The Fundamentals of Process Intensification, Ind. Eng. Chem. Res., 48, 2465-2474.

Welch, L. V. S. (1999): Low Consistency Refining of Mechanical Pulps, Ph.D. Thesis, Dep. Chem. Eng., University of British Columbia, Canada.

Manuscript received January 4, 2017

Accepted May 2, 2017 